\title{
Jornalismo
}

\section{Assessoria de imprensa não é jornalismo: conflito de interesses no Código de Ética dos Jornalistas Brasileiros}

\author{
Press office is not journalism: Conflict of interests in the Brazilian Journalists' \\ Code of Ethics \\ Virginia Pradelina da Silveira FonseCa \\ Professora do curso de Pós-Graduação em Comunicação e Informação da Universidade Federal do Rio Grande do Sul (UFRGS) - Porto Alegre, RS, Brasil. \\ <virginia@ufrgs.br>
}

\section{RESUMO}

O presente artigo sustenta a impossibilidade ética de conferir estatuto de jornalismo às atividades de assessoria de imprensa. Para isso, discute-se primeiramente o 'dever ser' do jornalismo e do jornalista, a partir de uma perspectiva deontológica, que se interroga sobre o imperativo categórico dessa prática social e dessa profissão. A seguir, analisam-se alguns artigos do Código de Ética dos Jornalistas Brasileiros, que parecem mais promover do que mitigar a confusão entre duas práticas sociais que, apesar de exercidas por jornalistas, têm obrigações morais específicas. Por fim, argumenta-se que, face ao seu imperativo dever de verdade e compromisso com o interesse público, o jornalismo ocupa uma posição no campo social que é de confronto e, eventualmente, tensão e conflito com os interesses das assessorias de imprensa. Conquanto constituam modalidades de comunicação, e embora possam colaborar entre si, não podem ser regulados pelo mesmo código deontológico.

Palavras-chave: Jornalismo; Ética jornalística; Assessoria de imprensa.

\section{ABSTRACT}

The present article declares the ethical impossibility to give press office activities the status of journalism. For that reason, in the first place it discusses the 'must be' of both journalism and the journalist from a deontolical perspective which wonders about the category imperative of such social practice as well as this profession. Next, it analyses some articles of the Brazilian Journalists Code of Ethics, which seem to promote more than mitigate the confusion between both social practices, which are carried out by journalists who have specific moral obligations. Finally, it argues that, in the face of its necessary commitment with the truth and the public interest, journalism has a position in the social area which is that of clashing and occasionally of conflict and tension with the interests of press agents. Even though these two areas may cooperate with one another, these modes of communication cannot be regulated by the same deontological code.

Keywords: Journalism; Journalistic ethics; Press office. 


\section{imperativo ético do jornalismo e do jornalista}

A discussão de temas que remetam ao campo da ética - como, por exemplo, o dever de verdade no jornalismo ou o compromisso do jornalista com a informação relevante e de interesse público, que levam ao debate mais amplo sobre a finalidade do jornalismo na vida social - contém o risco de alguma frustração a quem a propõe, porque inevitavelmente encontrará o argumento de que, na prática, as coisas são diferentes do preconizado pela teoria. Por isso, como defesa antecipada a uma provável ponderação desse tipo, lembra-se que a ética é do reino do que deve ser, não do que é. Ou, como explica o filósofo e psicanalista Jean-Bertrand Lefèvre Pontalis em entrevista à revista $V e j a{ }^{1}$, referindo-se a ensinamento de Sartre, de quem foi aluno na década de 1940: “o julgamento do fato trata sobre o que é; o julgamento do valor trata sobre o que deve ser" (Veja, 02/01/2013, p. 17). Ou ainda como afirma Furrow (2007, p. 181), na mesma direção: "A ética começa na abertura que a liberdade nos dá - o pensamento de que as coisas deveriam ser diferentes do que são, e a confiança de fazer com que aquele futuro se torne concreto".

Feita essa advertência, pode-se então formular algumas questões que motivam esta reflexão: que atribuição específica compete ao jornalismo na sociedade? Em que se distingue de outras formas de acesso ao real? Respostas a questões como estas constituem pressuposto para a discussão seguinte, objeto deste texto: qual o dever ético do jornalismo? Quais suas obrigações morais? Buscar respostas a perguntas como essas é uma estratégia para identificar a especificidade do jornalismo em relação a outras práticas comunicacionais, como as assessorias de imprensa, tomadas por alguns, de forma equivocada, como sendo uma forma de jornalismo, como se fossem atividades de mesma "natureza".

Embora neste texto não se desenvolva mais amplamente a discussão sobre as atribuições do jornalismo na esfera social, por uma questão de espaço e de delineamento, 
observa-se sucintamente que o jornalismo é uma prática social institucionalizada cuja finalidade é captar, produzir e divulgar informações de atualidade que se subordinem aos princípios de veracidade, relevância e interesse público. Os fatos sociais apreendidos segundo esses princípios são transformados em acontecimentos jornalísticos e tornados públicos através de um discurso, estruturado em variados gêneros (textos, imagens, áudios), posto em circulação em distintos suportes tecnológicos em períodos de tempo regular. Periodicidade, universalidade, atualidade e publicidade seriam suas características fundamentais, segundo Groth (2001).

Um dos aspectos que distingue o jornalismo de outros domínios do conhecimento é o fato de se ocupar de acontecimentos sociais da atualidade. As notícias, reportagens, entrevistas e mesmo os textos de opinião são registros de assuntos do momento, muitas vezes acontecimentos em curso e com consequências, desdobramentos. Assim, distancia-se da História, quando esta se ocupa do passado, mas também aproximase dela quando os historiadores se interessam pelo contemporâneo e passam a fazer uma historiografia do presente, ou do tempo imediato ${ }^{2}$. Assim, podemos dizer que o jornalismo se ocupa do presente social, como explica Karam:

O presente, na mediação jornalística, é a síntese que opera com reduções no tempo. Sua disseminação pública em linguagem especificamente jornalística permite o acesso imediato à aventura humana. Tal síntese e disseminação ampliam o universo de conhecimento social, reduzem a complexidade de um evento pela necessidade de acesso fácil e imediato das pessoas e multiplicam mensagens ao infinito para o máximo de participantes, num espaço curto de tempo."

(Karam, 2004, p. 30) 
Outro aspecto que compartilha com a história, mas o distancia da literatura, por exemplo, é o compromisso com a veracidade. Jornalismo não é ficção. As suas histórias têm de ter existência real, obrigatoriamente. Um fato, um evento, um fenômeno, uma opinião, uma declaração, um dado, enfim, tudo o que enseja um relato jornalístico encontra referência na realidade. O jornalista pode aproximar-se da literatura pela linguagem, pelo estilo, pelas técnicas de narração, mas não tem autorização ética para criar personagens, inventar "estórias" 3 .

Nesta perspectiva, faz-se necessária a discussão sobre um valor central para a instituição jornalística e para a cultura profissional: o dever de verdade. A relação com o valor verdade é fundamental para o argumento que se desenvolve adiante, que nega à assessoria de imprensa o estatuto de jornalismo.

\section{A verdade como valor absoluto}

Ao dever de verdade está subordinado o capital do jornalismo, a credibilidade (Berger, 1998). Contudo, a preocupação com a credibilidade não é exclusiva do jornalismo, mas de todas as áreas pertencentes à comunicação. “Quer esteja procurando informar o público sobre eventos dignos de serem noticiados, quer esteja tentando vender um produto com uma nova e atraente campanha publicitária, qualquer comunicador sério se preocupa em ser visto como uma fonte de informação confiável". Da mesma forma, "os estudantes de jornalismo, em especial, aprendem cedo que a credibilidade é a única moeda verdadeira que possuem", afirma Plaisance (2011, p. 51, grifo do autor).

O mesmo autor esclarece que a credibilidade está atrelada a muitos valores que orientam a prática da comunicação, quer a intenção seja informar, persuadir ou vender, e destaca: 1) senso de responsabilidade com os consumidores, com os interesses da comunidade e com a sociedade; 2) decência, honestidade e verdade; 3) rejeição da 
informação falsa e da fraude; 4) senso de concorrência justa; 5) proteção e promoção da reputação do setor da publicidade. E adverte que esses valores transcendem os setores da comunicação, pois são importantes na definição do comportamento ético de um modo geral (Plaisance, 2011, p. 52).

A relação do jornalismo com a verdade, no entanto, é distinta das demais áreas da comunicação. Como observa, dizer a verdade é obviamente um valor-chave nos meios de comunicação, razão por que é mencionado em vários códigos de ética de relações públicas, marketing e publicidade, que incluem comprometimentos formais quanto a honrar o valor da verdade. Isto quer dizer, explica, que se espera que as pessoas que usam os canais da mídia para convencer e defender evitem mentiras absolutas. A questão reside no fato de que, para essas áreas, a verdade tem caráter instrumental - ela é usada seletivamente, para promover uma causa, um produto, um interesse. Para o jornalismo, ao contrário, a verdade não é instrumental. Ela é um valor absoluto. "É importante não apenas por aquilo que realiza, mas como um fim em si mesmo. A busca da verdade é o que diferencia o jornalismo de todas as outras formas de comunicação" (Plaisance, 2011, p. 21).

Ao fazer a afirmação reproduzida acima, o autor não deixa de reconhecer o caráter complicado e ambíguo dessa noção grandiosa de verdade. Ele lembra, por exemplo, que a exatidão é uma dimensão da busca da verdade, razão que deve levar os jornalistas a serem meticulosos na verificação dos fatos e na utilização de fontes dignas de confiança. Acresce a isso, o fato de que a verdade raramente é revelada em um único elemento, mas resulta em geral de uma compilação progressiva de informações, um processo de revelação que poderá dar-se somente ao longo do tempo.

O dever de verdade é, portanto, um valor absoluto e um imperativo ético para a instituição jornalística e para o jornalista. É a crença do público nesse compromisso que confere credibilidade ao jornalismo, que o legitima como uma prática social 
capaz de fornecer um panorama dos acontecimentos mais importantes do mundo contemporâneo sem subordinar-se a qualquer outra razão que não seja o de cumprir o seu dever de informar. “O jornalista não age para obter resultados que não sejam o de bem informar o público; ele não tem autorização ética para perseguir outros fins que não este" (Bucci, 2000, p. 24). Agir de outro modo representaria subtrair o sentido da instituição e da profissão.

A proteção da credibilidade, aponta Plaisance (2011), orienta a maior parte das tomadas de decisão jornalísticas, refletindo-se nos diversos valores da profissão, expressos em documentos como o Código de Ética da Sociedade dos Jornalistas Profissionais $(\mathrm{SPJ})^{4}$. O autor reproduz parte do código que oferece quatro diretrizes fundamentais e apresenta pontos mais detalhados sobre o modo como estes devem ser entendidos e como devem determinar o trabalho dos jornalistas:

O esclarecimento público é o precursor da justiça e o fundamento da democracia. O dever do jornalista é promover esses fins buscando a verdade e fornecendo um relato justo e abrangente dos eventos e questões. Jornalistas conscientes de todos os meios de comunicação e especialistas lutam para servir ao público com rigor e honestidade. A integridade profissional é a base da credibilidade de um jornalista.

Principais diretrizes do código da SPJ:

- Buscar e relatar a verdade. Os jornalistas devem ser honestos, justos e corajosos ao coletar, relatar e interpretar as informações.

- Minimizar os danos. Os jornalistas éticos tratam as fontes, personagens e colegas como seres humanos dignos de respeito.

- Agir com independência. Os jornalistas não devem ter compromisso com qualquer interesse além do direito do público a ser informado.

- Ser responsáveis. Os jornalistas são responsáveis com os leitores, ouvintes, espectadores e com os colegas de profissão."

(Plaisance, 2011, p. 54) 
Observe-se, a propósito, que o primeiro dos valores relacionados trata justamente do dever de verdade ${ }^{5}$, que, apesar de também integrar o conjunto de valores das outras áreas da comunicação, não tem para elas - relações públicas, marketing, publicidade - o caráter absoluto que tem para o jornalismo. O dever de lealdade, por exemplo, é mais central para a área de relações públicas do que o é para o jornalismo.

Como as assessorias de imprensa mantêm com a verdade uma relação instrumental, isto é, como o compromisso com a verdade, nessas estruturas, é limitado pela conveniência do assessorado (governo, empresas, movimentos sociais, partidos políticos, organizações não-governamentais, etc., parte sempre interessada na promoção, no convencimento ou na defesa de uma causa, um produto, uma marca), as atividades que lhe são inerentes ${ }^{6}$, pertencem ao âmbito da comunicação organizacional e são, mesmo quando desempenhadas por profissionais com formação em jornalismo, nada além de estratégias, ou técnicas de planos de comunicação, que visam ao bom relacionamento com a imprensa. Essas atividades não constituem, contudo, forma de jornalismo.

Reafirmar o dever de verdade como um valor absoluto no jornalismo, constitui uma forma de filiação à corrente deontológica da teoria da ética ${ }^{7}$. Trata-se de uma filiação teórica pertinente ao tipo de indagação que se propõe neste texto, embora outras abordagens possam ser mais produtivas na análise de questões mais pontuais, como as relativas à responsabilidade do jornalista ou às consequências dos seus atos, por exemplo.

A teoria deontológica, abordagem concorrente da vertente utilitarista ${ }^{8}$, encontra fundamento em Kant, o grande filósofo da modernidade que procurou elaborar princípios de uma moral com valor universal. Rompendo com a ética grega antiga (Sócrates, Platão e Aristóteles), assim como destruindo todos os argumentos a respeito da existência de Deus, Kant propôs um sistema complexo que tem no dever o princípio 
norteador da ação moral. A esse sistema, o filósofo alemão deu o nome de imperativo categórico, que numa das traduções possíveis diz o seguinte: "Age de tal maneira que uses a humanidade, tanto na tua pessoa como na pessoa de qualquer outro, sempre e simultaneamente como fim e nunca simplesmente como meio" (Kant apud Costa, 2009, p. 98). Ou, simplesmente: “Age apenas segundo uma máxima tal que possas ao mesmo tempo querer que ela se torne lei universal" (Kant apud Costa, 2009, p. 98).

No imperativo categórico, são detalhados os deveres que temos como agentes morais. Agir de acordo com o imperativo categórico passa a ser um dever. Nessa perspectiva, a ação decorre de uma máxima9 ${ }^{9}$ e não de uma regra. Por ação moral, Kant refere-se ao fato de que testamos as nossas decisões ao perguntarmos se estas podem ser universalizadas - se seria razoável que todos aplicassem aquela decisão como padrão de comportamento. A ética kantiana é, portanto, um sistema moral que se baseia nas noções de dever, obrigação e princípios de conduta (Costa, 2009). Uma ação é julgada moralmente válida se o seu agente tiver compreendido e procurado cumprir o seu dever.

Quando aplicada ao jornalismo, esta corrente da teoria da ética revela-se adequada para se perguntar sobre o dever moral do jornalismo e dos jornalistas, como o que se pretende neste texto. Porque, para esta perspectiva, as conseqüências dos atos têm menor importância. Como explica Bucci:

O que importa é que o ato se revista das características de um imperativo categórico universal, quer dizer, que o ato se apóie em princípios que tenham a mesma validade para todos. [...]. Dizer a verdade é um autêntico imperativo categórico kantiano, pois corresponde a um princípio passível de universalização. [...]. Para o jornalista, dizer a verdade é um imperativo categórico fundamental. Azar das consequências."

(Bucci, 2000, p. 22) 
A ética de Kant diz respeito à ação correta e justa. Isso não quer dizer que uma ação baseada moralmente no princípio do dever não deva preocupar-se com as conseqüências, nem que uma ação baseada nas consequências seja destituída de princípios, como apontou Max Weber ao introduzir os conceitos de "ética da convicção" e "ética da responsabilidade" na famosa conferência de 1910 - "Política como vocação"10. Significa apenas atribuir um peso maior ao princípio do dever no momento da deliberação da ação ou do seu julgamento.

Esclarecida a perspectiva teórica que orienta esta reflexão, na seção a seguir passase à análise de alguns artigos do Código de Ética dos jornalistas brasileiros que se avalia como conflitantes com esta visão.

\section{Conflito de interesses no Código de Ética dos Jornalistas Brasileiros}

$\mathrm{O}$ esforço feito neste texto para distinguir jornalismo e assessoria de imprensa se justifica por uma especificidade brasileira, onde o Código de Ética que normatiza o funcionamento da profissão trata indistintamente jornalistas que atuam em organizações definidas a priori como jornalísticas, segundo os parâmetros aqui estabelecidos (jornais, revistas de informação, espaços jornalísticos em rádio, televisão e internet), e jornalistas que, no mercado de trabalho, atuam em assessorias de comunicação ou de imprensa, onde desenvolvem atividades de divulgação, promoção e defesa dos seus assessorados, ou, dito de outro modo, de mediação entre essas organizações e as instituições jornalísticas.

Diferentemente do que ocorre na maioria dos países democráticos ocidentais, essas duas profissões, distintas, são tratadas no Brasil como iguais, resultando, paradoxalmente, num conflito de interesses no próprio Código de Ética ${ }^{11}$. Por conta disso, como observa Bucci (2012, p. 91), "temos praticado o exercício de conciliar duas funções legítimas, dignas, justas e éticas, necessárias à informação da sociedade 
brasileira, mas que não constituem o mesmo ofício". Como jornalismo e assessoria de imprensa são duas profissões diferentes, com obrigações morais distintas, "não podem ser regidas por um mesmo Código de Ética" (Bucci, 2012, p. 91).

Seguindo a lógica do raciocínio que se vem desenvolvendo, veja-se a situação que se configura a partir do que afirma o inciso I do Art. 12 do referido Código:

\section{Art. 12. O jornalista deve:}

I - ressalvadas as especificidades da assessoria de imprensa, ouvir sempre, antes da divulgação dos fatos, o maior número de pessoas e instituições envolvidas em uma cobertura jornalística, principalmente aquelas que são objeto de acusações não suficientemente demonstradas ou verificadas.

Ora, as ressalvas concedidas ao jornalista no exercício da função de assessor de imprensa representam uma permissão, uma autorização, para que mantenha com o dever de verdade uma relação instrumental, seletiva, o que contraria frontalmente o compromisso ético do jornalista de honrar a verdade, valor de caráter absoluto na profissão, como afirma Plaisance (2011). Ressalvar as especificidades do assessor de imprensa no Código de Ética que o trata como jornalista significa dispensá-lo do dever de verdade, conceder-lhe a possibilidade de compromisso apenas com a verdade conveniente, promovendo a sobreposição do valor de lealdade para com o assessorado, próprio das outras profissões da área de Comunicação, como relações públicas e publicidade, ao valor de verdade em relação à sociedade, próprio dos jornalistas. 
Na mesma perspectiva, o Art. 7ํㅜ, inciso VI do código em referência, diz:

\section{Art. $7^{0}$ O jornalista não pode:}

$[\ldots]$

VI - Realizar cobertura jornalística para o meio de comunicação em que trabalha sobre organizações públicas, privadas ou não-governamentais, da qual seja assessor, empregado, prestador de serviço ou proprietário, nem utilizar o referido veículo para defender os interesses dessas instituições ou de autoridades a elas relacionadas.

Sobre este, Bucci (2012) já observara que o que mais impressiona é o que o texto deixa subentendido como prática permitida: que o jornalista possa ser, ao mesmo tempo, repórter num jornal e assessor de imprensa num órgão do governo ou numa $\mathrm{ONG}^{12}$. Parece que a intenção, aqui, foi admitir que o jornalista pode acumular funções, desde que não realize cobertura jornalística, para o veículo em que trabalha, sobre a organização (empresa, governo, movimento social, etc.) para a qual também trabalha. "Ocorre que a simples autorização tácita para esse acúmulo de atividades já é, em si mesma, antiética. E o nosso Código não apenas permite, ele consagra esse acúmulo de funções nitidamente conflitantes"', conclui Bucci (2012, p. 92).

Esses dois excertos parecem conflitar, internamente ao mesmo Código, com os artigos iniciais, Capítulo I - Do direito à informação, em que são reafirmados valores como o direito do cidadão ao acesso à informação de relevante interesse público, 
princípio segundo o qual os jornalistas não devem admitir restrições de qualquer tipo (Art. $2^{\circ}$ ).

Além disso, ao conceder ressalvas aos assessores de imprensa (Art. 12), parece configurar-se no Código de Ética uma situação em que estes têm privilégios não concedidos aos jornalistas vinculados a organizações jornalísticas, que ficam submetidos ao rigor do inciso I do Art. $2^{\underline{0}}$ do Capítulo I - Do direito à informação, que diz:

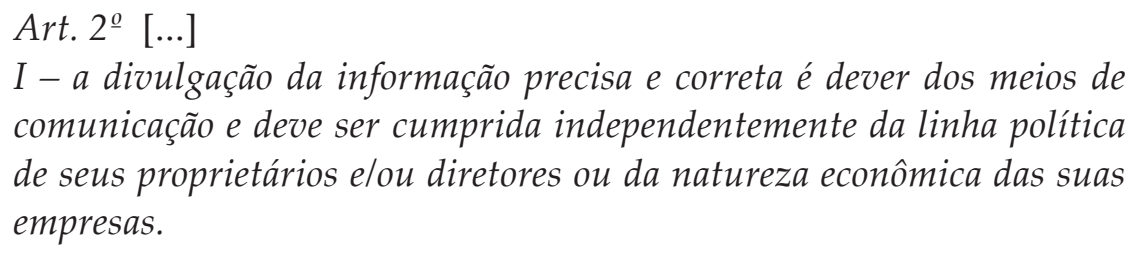
comunicação e deve ser cumprida independentemente da linha política de seus proprietários elou diretores ou da natureza econômica das suas empresas.

Assim sendo, os jornalistas vinculados a organizações jornalísticas não têm autorização do seu Código de Ética para manter relações de lealdade para com seus patrões, mas os assessores, sim. Da mesma forma, segundo o mesmo Código, Art. $4^{\circ}$, os jornalistas devem observar o compromisso fundamental com a verdade dos fatos, devendo pautar seu trabalho pela precisa apuração dos acontecimentos e pela sua correta divulgação. Os assessores, pelo contrário, teriam essa obrigação (dever) relativizada, porque, para estes, o compromisso com a verdade encontra o seu limite na conveniência. 
Alguém poderá argumentar que o dever de verdade do jornalista que atua nos meios jornalísticos tradicionais também encontra o seu limite na conveniência dos interesses e das políticas editoriais dos publishers. Aceita-se esse argumento, mas apenas em parte. Porque, para os empresários que têm no jornalismo o seu negócio, o dever moral de honrar a verdade, base da credibilidade dos seus produtos jornalísticos, tem um caráter tão imperativo quanto para o jornalista. No dia que o público deixar de confiar nas informações recebidas através dos jornais, por exemplo, a "mercadoria" também deixará de interessar aos anunciantes. Seria a débâcle do negócio.

Por tudo isso, vale reproduzir a pergunta de Bucci (2012, p. 94): “como uma categoria pode pretender ter um código de ética cujos artigos valem para alguns de seus integrantes e não valem para outros?"

Uma comparação com as profissões da área jurídica ajuda a esclarecer a confusão provocada, parte pelo Código de Ética, parte também pela formação universitária ${ }^{13}$ :

Juízes, advogados e promotores públicos são todos operadores do Direito, egressos das faculdades de Direito. Todos lidam com as leis, com a justiça, fazem funcionar o sistema jurídico. Não obstante, sabem que exercem funções distintas e, por isso, pertencem a ordens profissionais distintas, filiam-se a códigos de ética específicos. Não porque advogados pretendam promover a injustiça em oposição a juizes que pretendem fazer valer a lei, mas porque seus ofícios concentram particularidades inconciliáveis e, sem demérito para promotores, advogados e juízes, essas três categorias são diferentes. É assim que, ao se tornar juiz de Direito, um advogado deve se desfiliar da Ordem dos Advogados do Brasil, devolvendo sua carteira à entidade."

(Bucci, 2012, p. 96) 
O mesmo não ocorre com os ofícios ${ }^{14}$ de jornalista e de assessor de imprensa no Brasil, razão por que se compartilha com o autor a tese de que há conflito de interesse no Código de Ética dos Jornalistas Brasileiros, situação que se configura claramente com a sujeição de profissões com obrigações morais distintas a um mesmo código deontológico.

São as obrigações morais, portanto, o principal fator a distinguir essas duas práticas pertencentes ao mesmo campo da comunicação, e não as rotinas de trabalho ou a formação universitária, o diploma. Por essa razão, não poderiam estar submetidas ao mesmo código de ética.

\section{Considerações finais}

Com este texto, persegue-se o propósito de promover a discussão dos valores morais do jornalismo e dos jornalistas, tema de projeto de pesquisa sobre ética jornalística que tem, entre outros objetivos, a finalidade de ampliar e aprofundar a análise crítica da ação, do ponto de vista moral, de meios e profissionais. Num tempo de superabundância de informação, em que praticamente todas as formas de organização da vida social (empresas, governos, instituições, movimentos sociais, organizações não governamentais, partidos políticos, etc.) produzem e põem em circulação as suas próprias informações e opiniões, cabe ao jornalista, mais do que em qualquer época, legitimar-se ante a sociedade oferecendo informação confiável, resultante de rigoroso trabalho de apuração e contextualização. Por rigor no processo de apuração entende-se também a correção moral de todas as ações dos jornalistas e das empresas ${ }^{15}$ para as quais trabalham. Esta seria, talvez, uma das únicas formas de evitar a morte do jornalismo e de preservá-lo como instituição - "fonte de esclarecimento público, precursor da justiça e fundamento da democracia", como afirma o Preâmbulo do Código de Ética da Sociedade dos Jornalistas Profissionais (SJP). Isso significa que a 
ética pode ser o fator de distinção do jornalismo ante as muitas outras formas de acesso à realidade, hipótese já levantada por Christofoletti $(2010)^{16}$ e à qual este texto se filia. Porque os fins não justificam os meios. "A maneira como atingimos nossos objetivos diz tanto sobre quem somos quanto aquilo que escolhemos como nossos objetivos", lembra-nos Plaisance (2011, p. 36, grifo do autor).

O tipo de preocupação que motiva este texto tangencia também a questão da identidade jornalística, uma vez que a confusão entre jornalismo e assessoria de imprensa constitui fator de fragmentação identitária, que está para além da discussão sobre a exigência ou não do diploma para o exercício da profissão, tema do qual não se tratou aqui, mas que se encontra muito bem abordado em Lopes (2011).

A indistinção entre atividades profissionais com obrigações morais diferentes tem conseqüências, e leva a situações, como as ocorridas no segundo semestre de 2012, em que a crítica ao jornalismo parece partir da expectativa de que, em alguns casos, os jornalistas devessem se portar como assessores de imprensa. Nesse ano, os meios jornalísticos do Brasil e do exterior deram ampla cobertura a dois acontecimentos políticos em particular: o julgamento do mensalão ${ }^{17}$ e a Operação Porto Seguro ${ }^{18}$. O destaque dado a esses eventos e o tipo de cobertura realizada provocaram reações de alguns grupos que, através das redes sociais e blogs, principalmente, acusaram a imprensa ${ }^{19}$ de promover uma campanha de criminalização do Partido dos Trabalhadores e do ex-presidente Lula.

Esse tipo de crítica, por ser genérica, decorre de certo desconhecimento dos valores do jornalismo, tais como descritos no Código de Ética da SPJ. Tanto num caso quanto no outro, a cobertura jornalística cumpriu a sua obrigação moral de noticiar com destaque acontecimentos da atualidade, revestidos de relevância e de interesse público. Além disso, com indiscutíveis valores-notícia - como o ineditismo do processo, a presença de personalidades do alto escalão do governo e do partido na condição de réus (caso 
do mensalão) e o envolvimento de pessoa da intimidade do ex-presidente em esquema de corrupção (caso da Operação Porto Seguro). Esses temas podem ser desconfortáveis e constrangedores para os apoiadores e simpatizantes do partido e seu líder, mas de alto valor jornalístico.

Pode-se não compartilhar das interpretações, das opiniões, dos enquadramentos determinados por políticas editoriais, mas daí a afirmação genérica de que a cobertura jornalística como um todo significasse "uma estratégia das elites" para criminalizar o partido governista e a figura do seu principal líder, argumento utilizado pelos críticos, parece-nos um exagero, porque tanto em um caso como em outro as denúncias não partiram dos meios jornalísticos, mas de personagens internos à coalizão governista (caso do mensalão) e da Polícia Federal (caso da Operação Porto Seguro). A crítica à imprensa, nesse aspecto, surpreende por ter surgido, em alguns casos, no próprio campo jornalístico.

Plaisance (2011) argumenta que se deve estudar ética para que a ação relativa a questões sociais e morais não seja apenas uma projeção de preferências sociais arbitrárias. Sem uma filosofia abrangente, diz ele, é menos provável que as deliberações éticas transcendam as reações simplistas de caráter instintivo, as preferências partidárias veladas e as generalizações grosseiras em relação aos sistemas e ao comportamento da mídia. A crítica descrita acima pode, assim, ser entendida muito mais como a expressão de uma preferência partidária disfarçada e menos como uma apreciação da atuação da imprensa provocada por alguma transgressão moral cometida nesses casos específicos ${ }^{20}$. Esperar que a imprensa agisse de outro modo, esmaecendo os fatos e as personagens envolvidas, por exemplo, constituiria o equívoco de confundir a prática jornalística com a prática da assessoria de imprensa, tal qual faz o Código da FENAJ. No entanto, jornalismo não é assessoria de imprensa. 


\section{REFERÊNCIAS}

BERGER, Christa. Campos em confronto: a terra e o texto. Porto Alegre: Ed. Universidade/UFRGS, 1998.

BUCCI, Eugênio. Sobre ética e imprensa. São Paulo: Companhia das Letras, 2000.

. A imprensa e o dever de liberdade. São Paulo: Contexto, 2012.

Código de Ética da Sociedade dos Jornalistas Profissionais (SPJ). Disponível em: <http://www.spj.org/ ethicscode-port.asp>. Acesso em: 25 jan. 2013.

Código de Ética dos Jornalistas Brasileiros (FENAJ, 2007). Disponível em: <http://www.fenaj.org.br/>. Acesso em 24 jan. 2013.

COSTA, Caio Túlio. Ética, jornalismo e nova mídia: uma moral provisória. Rio de Janeiro: Ed. Jorge Zahar, 2009.

CHRISTOFOLETTI, Rogério. Valores, ordenamentos de conduta e subsistência do jornalismo. Comunicação apresentada ao XX Encontro Anual da Compós. Disponível em: <http://www.compos.org.br/pagina.php? menu=8\&mmenu=\&ordem=1D\&grupo1=\&grupo2=>. Acesso em: 26 jan. 2013.

FURROW, Dwight. Ética: princípios-chave em filosofia. Tradução de Fernando José R. da Rocha. Porto Alegre: Artmed, 2007.

GROTH, Otto. O poder cultural desconhecido: fundamentos da Ciência dos Jornais. Petrópolis: Vozes, 2011.

KARAM, Francisco José. A ética jornalística e o interesse público. São Paulo: Summus, 2004.

LACOUTURE, Jean. A História Imediata. In: LE GOFF, Jacques; CHARTIER, Roger; REVEL, Jacques. A história nova. 4. ed. São Paulo: Martins Fontes, 1998.

LOPES, Fernanda Lima. O jornalista e suas lutas para a construção de si em torno do diploma. In: BARBOSA, Marialva Carlos; RIBEIRO, Ana Paula Goulart (Orgs.). Comunicação e História: partilhas teóricas. Florianópolis: Insular, 2011. pp. 115-133.

PLAISANCE, Patrick Lee. Princípios para uma prática responsável. Porto Alegre: Penso, 2011.

PONTALIS, Jean-Bertrand. O elogio da verdadeira amizade. In: Revista Veja, n. 2302, p. 15, 2 jan. 2013.

VALLS, Álvaro L. M. O que é ética. São Paulo: Brasiliense, 2008. 


\section{NOTAS}

1 O escritor morreu em 15/01/2013, em Paris, logo após a publicação da entrevista.

2 De acordo com Lacouture (1998), a história imediata é uma forma de fazer história que não pode ser delimitada a um determinado enquadramento específico. Ela se caracteriza por ser construída num cenário em que há uma proximidade muito grande entre a redação da obra e o tema tratado, além de uma proximidade material do autor com aquilo que está sendo narrado ou estudado.

3 Narrativa de ficção.

4 Sigla para Society of Professional Journalists. A íntegra do documento está disponível em <http://www.spj. org/ethicscode-port.asp $>$.

5 Por uma questão de espaço e de delineamento de pesquisa, não se aborda neste texto os outros valores relacionados na citação.

6 Planejar contatos dos seus assessorados com os jornalistas, organizar entrevistas, preparar press releases, organizar clippings, sugerir e promover pautas, organizar e promover eventos, etc.

7 Define-se ética como a ciência dos costumes ou dos atos humanos que tem como objeto a moralidade. É a parte da filosofia que procura determinar a finalidade da vida humana e os meios para alcançá-la (Valls, 2008). Em grande parte da bibliografia, os termos ética e moral são tomados como equivalentes. Contudo, procura-se conceituar a moral como "o conjunto de regras de conduta consideradas válidas, quer de modo absoluto para qualquer tempo ou lugar, quer para grupo ou pessoa determinada" (Valls, 2008) e ética como "princípios que guiam a ação privada do homem em um grupo social determinado em que a escolha é possível" (Costa, 2009, p. 58).

8 O Utilitarismo é uma doutrina segundo a qual uma ação é considerada certa ou errada, do ponto de vista moral, conforme suas consequências. O que define uma ação correta e boa é a quantidade de bemestar que possa proporcionar ao maior número de pessoas. Segundo Furrow (2007), sua elaboração mais detalhada foi feita por Jeremy Bentham (1748-1832), depois desenvolvida e aprofundada por vários filósofos e economistas, com destaque para John Stuart Mill (1806-1873).

9 Princípio segundo o qual o sujeito racional deve agir, um imperativo. É o princípio subjetivo da ação que contém a regra prática que determina a razão em conformidade com as ações do sujeito (Costa, 2009).

${ }^{10}$ A ética da convicção atribuiria uma vigência forte aos valores, um caráter absoluto a eles, sem se importar com as consequências. Já o adepto da ética da responsabilidade aproxima-se do utilitarismo, que avalia a ação segundo as suas consequências. Aproxima-se apenas, porque Weber nunca foi um utilitarista. Na verdade, é um neokantiano, para quem as éticas da convicção e da responsabilidade não são excludentes, mas complementares, e juntas moldariam "o homem autêntico, um homem que pode ter a vocação para a política (Weber apud Costa, 2009, pp. 101-113). 
${ }^{11}$ O Código de Ética dos Jornalistas Brasileiros é um documento da Federação Nacional dos Jornalistas (FENAJ) aprovado em congresso realizado em Vitória (ES), em 2007. Sua íntegra pode ser encontrada no site <http://www.fenaj.org.br/>.

12 Sigla para Organização Não Governamental.

${ }^{13}$ No Brasil, a formação universitária dos jornalistas se dá, na maioria dos casos, em cursos de Comunicação, com habilitação em Jornalismo, desde 1969, ano em que entrou em vigor o Decreto-Lei 972/1969, que passou a exigir diploma de curso superior em jornalismo para o exercício profissional. Desde então, o jornalismo passou a ser uma modalidade, uma especialidade do campo comunicacional. Em 2009, o Supremo Tribunal Federal (STF) considerou inconstitucional a legislação que exigia o diploma.

${ }^{14}$ Apesar da existência de distinção conceitual entre ofício e profissão, neste artigo os termos são tomados no sentido comum, como sinônimos.

${ }^{15}$ Sejam elas empresas privadas, públicas, estatais, comunitárias ou qualquer outra configuração.

${ }^{16}$ Hipótese defendida durante a comunicação "Valores, ordenamentos de conduta e subsistência do jornalismo", apresentada ao GT Estudos de Jornalismo no Encontro Anual da Compós de 2011, em Porto Alegre (UFRGS).

${ }^{17}$ Esquema de compra de apoio parlamentar empreendido durante o primeiro mandato do presidente Luís Inácio Lula da Silva (2003-2006). O termo 'mensalão' foi dado pelo delator do esquema, Dep. Roberto Jefferson, e assim apropriado pela imprensa para se referir ao que resultou na Ação Penal 470, processo judicial em que o STF condenou em 2012, entre outros, toda a cúpula do Partido dos Trabalhadores (PT) à época dos acontecimentos.

${ }^{18}$ Nome da operação deflagrada pela Polícia Federal no segundo semestre de 2012 que desbaratou esquema de corrupção envolvendo, entre outros, a chefe de gabinete da Presidência da República em São Paulo, Rosemary Noronha, que, segundo a imprensa, mantinha relação de intimidade com o ex-presidente Lula há quase duas décadas.

${ }^{19}$ Designação genérica para o conjunto das instituições jornalísticas, independentemente da sua base tecnológica.

${ }^{20}$ Num ou noutro caso, pode ter ocorrido falha moral por parte de algum veículo ou jornalista, situação que requereria, entretanto, análise específica.

\section{Endereço da autora:}

Virginia Pradelina da Silveira Fonseca <virginia@ufrgs.br>

Universidade Federal do Rio Grande do Sul - Faculdade de Biblioteconomia e Comunicação

Rua Ramiro Barcellos, 2705 - Santana

CEP 90035-007, Porto Alegre, RS, Brasil 